\title{
High performance polyimide films containing benzimidazole moieties for thin film solar cells
}

https://doi.org/10.1515/epoly-2019-0059

Received July 15, 2019; accepted August 10, 2019.

\begin{abstract}
In order to match the fabrication process of flexible Copper-Indium-Gallium-Selenide (CIGS) solar cell, a series of polyimides (PIs) with high initial decomposition temperatures (Td) were prepared from 6,4'-diamino-2'-trifluoromethyl-2-phenylbenzimidazole (DATFPBI), p-phenylenediamine (p-PPD), and S-type biphenyl dianhydride (s-BPDA) using a sequential copolymerization, casting, and thermal imidization process. The physical properties of the PIs were found to be effectively modified by adjusting both the ratio of the rigid momomers and the thermal imidization process. With the introduction of DATFPBI, the polymers showed significant improvements in thermal stability, thermal expansion, moisture absorption and mechanical properties. PIPBId, one of the synthesized PI film, exhibited an excellent comprehensive performance: a glass transition temperature of $368^{\circ} \mathrm{C}$, a tensile modulus of $6.8 \mathrm{GPa}$, a linar coefficient thermal expansion (CTE) of $16.8 \mathrm{ppm} / \mathrm{K}$, and a moisture absorption of $1.42 \%$. Furthermore, $\mathrm{Td}$ of this thin film was up to $524^{\circ} \mathrm{C}$,which indicated that the PIPBId film is a competitive candidate as the flexible substrate for CIGS, Copper-Zinc-Tin-Sulphide (CZTS) solar cell and flexible printed circuit boards (FPCB) where high process temperature is necessary.
\end{abstract}

Keywords: polyimides; thermal stability; benzimidazole; linar coefficient of thermal expansion (CTE)

\section{Introduction}

Aromatic PIs exhibit outstanding thermal stability, excellent mechanical properties and dimensional stability,

\footnotetext{
* Corresponding author: Hongbo Liu, School of Applied Chemistry and Biological Technology, Shenzhen Polytechnic, Shenzhen 518055, P.R. China, e-mail: 80128292@qq.com

Pengchang Ma and Chuntao Dai, Zhongshan Polytechnic, Zhongshan, 528404, P.R. China
}

low dielectric constant, and electric insulation performance in a wide temperature range. Aromatic PIs are generally obtained from aromatic dianhydride compounds and aromatic diamine compounds, synthesized and processed by different routes (1-10). Aromatic PI films have been widely used in high-technology fields, such as electronics industry, aerospace industry and automobile manufacture $(11,12)$. Benefited from its excellent comprehensive properties, PI films have been widely used as heatresistant insulating materials, flexible printed circuits, dielectric and flexible connecting materials for multichip model systems, tape automated bonding, substrates for flexible solar cells or flexible displays, and lithium-ion battery separators (8-11). However, with the development of wireless communications, polyimide films with higher modulus, lower linear thermal expansion coefficient (CTE), lower dielectric constant, higher hygroscopicity are requested to meet the requirement for high-frequency low loss circuit (13-15). In the portable energy product field, the use of the PI film as substrates can effectively improve the flexibility and reduce the weight of the solar cells normally using CIGS or CZTS photovoltaci materials. To meet this requiement, the initial decomposition temperature of the PI film should be high enough. However, conventional commercial PI films cannot to be compatible with the high temperature deposition process of the CIGS solar cell. For example, the $\mathrm{T}_{d}$ of two commercial PI films Kapton and Upilex-S are 500 and $520^{\circ} \mathrm{C}$, respectively, which cannot sustain the high temperature fabrication process of CIGS and CZTS solar cells which is usually above $530^{\circ} \mathrm{C}(16,17)$. In addition to the excellent thermal stability, PIs for flexible solar cells are also requested to be with low CTE and high hygroscopicity.

Great efforts have been made to modify the PI materials to improve their properties, such as making it composited with inorganic materials or other polymers (18-20), copolymerized with other dianhydrides or diamines building blocks (21-23), uniaxially or biaxially stretching the partially chemically imidized PAA film with post-heating treatment (24-26), and electrospinning method from a PAA solution orpolyimide solution with 
post-heating (27). However, most of those modification methods can only improve certain properties of the polyimide film. It is still a big challenge to have a balanced comprehensive performance of the film.

One efficient way to modify the PI structure is to introduce poly(imide-benzimidazole)s containing benzimidazole rings and poly(imide-benzoxazole) containing benzoxazole rings. Due to the oxygen or nitrogen-heterocyclic polymer structure, these molecules have outstanding heat resistance, high strength, and high moduli characteristics $(28,29)$. However, the flexibility of these films is poor because of the high rigidity of the rodlike chains. Furthermore, the water absorption behavior of these films as flexible substrates is too high to be applied in solar cells and electronic field (30).

In this paper, a series of PIs were synthesized to be with high $T_{d}$ which is suitable for flexible CIGS solar cell deposition at high temperature, together with a lower CTE and lower water absorption. We find that the introduction of rigid structures without hydrophilic groups into polymer chains is an effective way to adjust and optimize their properties of PIs, especially for minishing the water absorption (17-19). We modified the polyimide chain structure by introducing a third component, a rigid diamine, benzimidazole 6,4'-diamino-2'-trifluoromethyl-2phenylbenzimidazole (DATFPBI), into the Upilex-S-style PI to improve the overall performance of the PI film. A series of polyimide films with different proportions of benzimidazole groups were prepared by copolymerization. The influence of the content of DATFPBI on thermal stability, mechanical property, moisture absorption, dimensional stability and electrical property were characterized and disccussed.

\section{Experimental}

\subsection{Materials}

6,4'-diamino-2'-trifluoromethyl-2-phenylbenzimidazole (DATFPBI) was prepared according to the synthetic method as reported by Hyungsam Choi and his coworkers (31). 4,4'-biphenyltetracarboxylic dianhydride (s-BPDA) was purchased from Shenzhen Zike Biotechnology Co. Ltd., P-phenylenediamine (p-PPD) was obtained from Shanghai Yihe Biotechnology Co. Ltd., Phthalic anhydride (PA, chemical pure) was purchased from Beijing Chemical Plant., s-BPDA, p-PPD, and PA were all purified by sublimation under reduced pressure. $\mathrm{N}, \mathrm{N}^{\prime}$-dimethyl Acetylamine (DMAc) was purchased from Tianjin Chemical Reagent Co., Ltd (analytical pure).

\subsection{Preparation of PI films}

The polymerization was done in DMAc under a nitrogen atmosphere at room temperature for $12 \mathrm{~h}$, and a series of PAA solutions were obtained first (Table 1 and Scheme 1). The resulted PAAs with a solid content of $10 \mathrm{wt} \%$ gave a dynamic viscosity of 40 to $45 \mathrm{~Pa} \cdot \mathrm{s}$ at $25^{\circ} \mathrm{C}$. After a filtration of the PAA solution with a G2 funnel, the PAA filtrate was casted onto a glass substrate and followed by air-drying on a horizontal platform for $3-6 \mathrm{~h}$ at $65^{\circ} \mathrm{C}$. The obtained gel film was cured via a four step heat treatment procedure: heating at a rate of $2.5^{\circ} \mathrm{C} / \mathrm{min}$ from $65^{\circ} \mathrm{C}$ to $150^{\circ} \mathrm{C}$ and held at $150^{\circ} \mathrm{C}$ for $15 \mathrm{~min}$, then rising from $150^{\circ} \mathrm{C}$ to $250^{\circ} \mathrm{C}$ at $2.5^{\circ} \mathrm{C} / \mathrm{min}$ and held at $250^{\circ} \mathrm{C}$ for $20 \mathrm{~min}$, followed by heating from $250^{\circ} \mathrm{C}$ to $300^{\circ} \mathrm{C}$ at $2.5^{\circ} \mathrm{C} / \mathrm{min}$ and held at $300^{\circ} \mathrm{C}$ for $5 \mathrm{~min}$, and finally, from $300^{\circ} \mathrm{C}$ to $395^{\circ} \mathrm{C}$ at $2.5^{\circ} \mathrm{C} / \mathrm{min}$ and held at $395^{\circ} \mathrm{C}$ for $8 \mathrm{~min}$. After naturally cooling down to room temperature, the film was peeled off from the glass substrate after immersed into warm water. Then, a series of PIPBI polyimide films with the DATFPBI content of $0,5,10,15,20 \mathrm{wt} \%$, respectively, were prepared follow the similar procedure and the thickness of the films was $\sim 25 \pm 1 \mu \mathrm{m}$.

\subsection{Characterization}

The dynamic viscosity of the PAAs was measured by NFJ-1 rotary viscometer. The Fourier-transform infrared spectroscopy (FTIR) spectrum of the film was performed by a Bruker VERTEX 70 spectrometer with reflection mode. The thermal properties of the film were analyzed on a TGA Q50 (TA Instruments). The samples were heated from $60^{\circ} \mathrm{C}$ to $800^{\circ} \mathrm{C}$ with a heating rate of $10^{\circ} \mathrm{C} / \mathrm{min}$ and a nitrogen flow rate of $60 \mathrm{~mL} / \mathrm{min}$. The static mechanical properties of the PI films were measured using a universal testing machine (Instron Model 1122), the sample size was $30 \mathrm{~mm} \times 5 \mathrm{~mm}$, the tensile rate was $5 \mathrm{~mm} / \mathrm{min}$. The dynamic mechanical thermal analysis (DMA) of the film was recorded with a type dynamic mechanical thermal analyzer (Rheometric Scientific DMTA-V), the sample

Table 1: Composition of BPDA/PPD-DATFPBI films (molar ratios).

\begin{tabular}{lccc}
\hline Entry & S-BPDA & p-PPD & DATFPBI \\
\hline PIPBI $_{a}$ & 100 & 100 & 0 \\
PIPBI $_{b}$ & 100 & 95 & 5 \\
PIPBI $_{c}$ & 100 & 90 & 10 \\
PIPBI $_{d}$ & 100 & 85 & 15 \\
PIPBI $_{e}$ & 100 & 80 & 20 \\
\hline
\end{tabular}



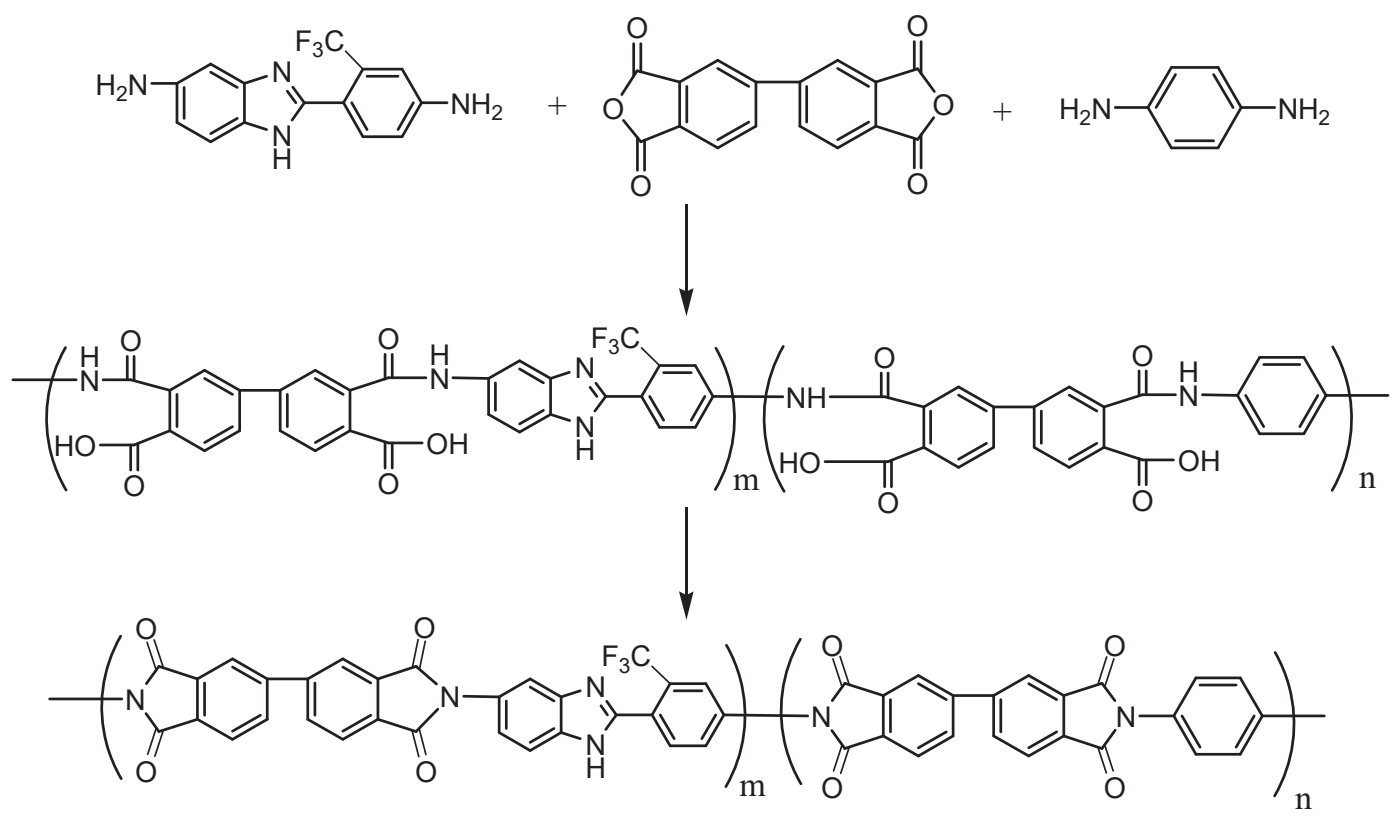

Scheme 1: Synthesis process of BPDA/PPD-DATFPBI films $\left(\mathrm{PIPBI}_{\mathrm{a}} \sim \mathrm{PIPBI}_{\mathrm{e}}\right)$.

size was $5 \mathrm{~mm} \times 30 \mathrm{~mm}$, the heating rate was $3^{\circ} \mathrm{C} / \mathrm{min}$, $1 \mathrm{~Hz}$. The linear thermal expansion coefficient (CTE) of the film was measured by a thermomechanical analyzer (TMA, Q400) with a sample size of $5 \mathrm{~mm} \times 15 \mathrm{~mm}$ at a heating rate of $10^{\circ} \mathrm{C} / \mathrm{min}$. The mechanical properties and CTE were characterized by testing at least 5 samples. The dielectric constant was measured using an AC impedance spectrometer (SI 1260) manufactured by Solartron. The diameter of the round copper electrode was $10 \mathrm{~mm}$, working voltage was $1000 \mathrm{mV}$, the frequency was $1 \mathrm{kHz}$. Moisture absorption rate of the film was measured according to standard ASTM D5229.

\section{Results and discussion}

\subsection{Preparation of PI films}

Table 2 showed the effects of the heating rate and imidization procedure on the properties of the BPDA/ PPD-DATFPBI film, respectively. The experimental results showed that the CTE, the modulus and elongation at break increased gradually with the increase of heating rate, as well as the CTE with more heating steps, while the CTE slightly decreased with the increase of heating step process, which suggested that thermal imidization parameters were crucial for not only the completeness of the reaction, but also the mechanical properties and the CTE of the film.
Compared with thermoplastic polyimides, nonthermoplastic polyimides such as BPDA/PPD and BPDA/ PPD-DATFPBI, the backbone of which is rigid and the molecular chain is not sufficiently moved during thermal imidization, are found that their physical properties strongly depend on the thermal imidization conditions (32). That is, the more rigid polyimide structure is, the more strongly physical properties are dependent on the preparation conditions, such as one-step or multi-step heat treatment, heating rate and final heat treatment temperature, etc. $(32,33)$. In particular, we have studied the influence of multi-step heat treatment and heating rate on the thermal expansion coefficient of the films. Generally, for a PI film with rod-like BPPD/PPD or BPPD/PPD-DATFPBI, the more thermal imidization steps give the higher molecular orientation, and the lower CTE and higher modulus (32,34-36). Whereas the higher modulus and CTE were obtained with the heating rate increased. The former was attributed to the higher molecular chain orientation in the rapid heating process, while the latter depends not only on the molecular chain orientation, but also on relaxation. In the rapid heating process, the molecular chain can be rapidly oriented, but the relaxation is insufficient. The combined action of the two factors gave the higher CTE. Additionally, the final heat treatment temperature should be higher than the glass transition temperature $\mathrm{T}_{\mathrm{g}}$ of the film (37). According to the experimental results on the characteristics of BPDA/ PPD-DATFPBI type polyimide film, the heat treatment process of preparing BPDA/PPD-DATFPBI polyimide followed the above four-step have been optimized. 
Table 2: Effect of heating rate on the properties of $\mathrm{PIPBI}_{d}$ film.

\begin{tabular}{lccc}
\hline Heating rate* & $\begin{array}{c}\text { Tensile modulus } \\
(\mathrm{GPa})\end{array}$ & $\begin{array}{c}\text { CTE } \\
\left(\mathrm{ppm} /{ }^{\circ} \mathrm{C}\right)\end{array}$ & $\begin{array}{c}\text { Elongation } \\
(\%)\end{array}$ \\
\hline $\mathrm{A}$ & $5.7 \pm 0.15$ & $17.7 \pm 0.1$ & $7.4 \pm 0.1$ \\
$\mathrm{~B}$ & $6.0 \pm 0.17$ & $17.9 \pm 0.12$ & $7.8 \pm 0.15$ \\
$\mathrm{C}$ & $6.8 \pm 0.2$ & $18.3 \pm 0.18$ & $8.4 \pm 0.2$ \\
$\mathrm{D}$ & $5.7 \pm 0.15$ & $17.7 \pm 0.1$ & $7.4 \pm 0.1$ \\
$\mathrm{E}$ & $6.1 \pm 0.16$ & $17.4 \pm 0.1$ & $7.7 \pm 0.12$ \\
$\mathrm{~F}$ & $7.0 \pm 0.2$ & $16.8 \pm 0.07$ & $8.1 \pm 0.15$ \\
\hline
\end{tabular}

*Heating rate $\mathrm{A}$ : heated to $395^{\circ} \mathrm{C}$ at $2.5^{\circ} \mathrm{C} / \mathrm{min}$ from $65^{\circ} \mathrm{C}$, and held at $395^{\circ} \mathrm{C}$ for $48 \mathrm{~min}$. Heating rate $\mathrm{B}$ : heated to $395^{\circ} \mathrm{C}$ at $5^{\circ} \mathrm{C} / \mathrm{min}$ from $65^{\circ} \mathrm{C}$, and held at $395^{\circ} \mathrm{C}$ for $84 \mathrm{~min}$. Heating rate $\mathrm{C}$ : heated to $395^{\circ} \mathrm{C}$ at $10^{\circ} \mathrm{C} / \mathrm{min}$ from $65^{\circ} \mathrm{C}$, and held at $395^{\circ} \mathrm{C}$ for $117 \mathrm{~min}$. After imidization, all films were naturally cooled down to room temperature. Heating rate D: imidized by an one-step procedure - heated to $395^{\circ} \mathrm{C}$ at $2.5^{\circ} \mathrm{C} / \mathrm{min}$ from $65^{\circ} \mathrm{C}$, and held at $395^{\circ} \mathrm{C}$ for $48 \mathrm{~min}$. Heating rate $\mathrm{E}$ : imidized by a two-steps process - heated to $200^{\circ} \mathrm{C}$ at $2.5^{\circ} \mathrm{C} / \mathrm{min}$ from $65^{\circ} \mathrm{C}$ and held at $200^{\circ} \mathrm{C}$ for $36 \mathrm{~min}$, then heated to $395^{\circ} \mathrm{C}$ at $2.5^{\circ} \mathrm{C} / \mathrm{min}$ and held at $395^{\circ} \mathrm{C}$ for $12 \mathrm{~min}$. Heating rate $\mathrm{F}$ : imidized by a four-steps process - heated to $150^{\circ} \mathrm{C}$ at $2.5^{\circ} \mathrm{C} / \mathrm{min}$ from $65^{\circ} \mathrm{C}$ and held at $150^{\circ} \mathrm{C}$ for $15 \mathrm{~min}$, heated to $250^{\circ} \mathrm{C}$ at $2.5^{\circ} \mathrm{C} / \mathrm{min}$ and held at $250^{\circ} \mathrm{C}$ for $20 \mathrm{~min}$, heated to $300^{\circ} \mathrm{C}$ at $2.5^{\circ} \mathrm{C} / \mathrm{min}$ and held at $300^{\circ} \mathrm{C}$ for $5 \mathrm{~min}$, heated to $395^{\circ} \mathrm{C}$ at $2.5^{\circ} \mathrm{C} / \mathrm{min}$ and held at $395^{\circ} \mathrm{C}$ for $8 \mathrm{~min}$. After imidization, all films were naturally cooled down to room temperature.

\subsection{FTIR spectra}

The above PIPBI and PIPBI films were characterized by FTIR. As shown in Figure 1, the $\mathrm{N}-\mathrm{H}$ stretching bands of the imidazole ring are observed at $3200-3400 \mathrm{~cm}^{-1}$. The asymmetric $\mathrm{C}=\mathrm{O}$, symmetric $\mathrm{C}=\mathrm{O}$ and the $\mathrm{C}=\mathrm{C} / \mathrm{C}=\mathrm{N}$ stretching bands appear at 1780, 1718 and $1625 \mathrm{~cm}^{-1}$ for all the polyimides. The asymmetric C-F and symmetric C-F stretching bands appear at 1173 and $1133 \mathrm{~cm}^{-1}$ respectively. The absorption peak at $1375 \mathrm{~cm}^{-1}$ is usually considered as the characteristic of imide and evaluates as the criterion of imidization degree. From all the above, the complete imide cyclization is accomplished as described.

\subsection{Thermal stability}

The thermal stability of the hybrid films was evaluated from TGA curves (Figure 2 and Table 3). The PIPBI film without DATFPBI gave the initial decomposition temperature $\left(\mathrm{T}_{\mathrm{d}}\right)$ of $501^{\circ} \mathrm{C}$ under a dynamic nitrogen environment. It was found that with the DATFPBI composition increasing, the thermal stability of the films increased obviously, with $\mathrm{T}_{d}$ at $509^{\circ} \mathrm{C}, 516^{\circ} \mathrm{C}, 524^{\circ} \mathrm{C}$ for DATFPBI content of $5 \%, 10 \%$, $15 \%$, respectively. Further increase of the DATFPBI content

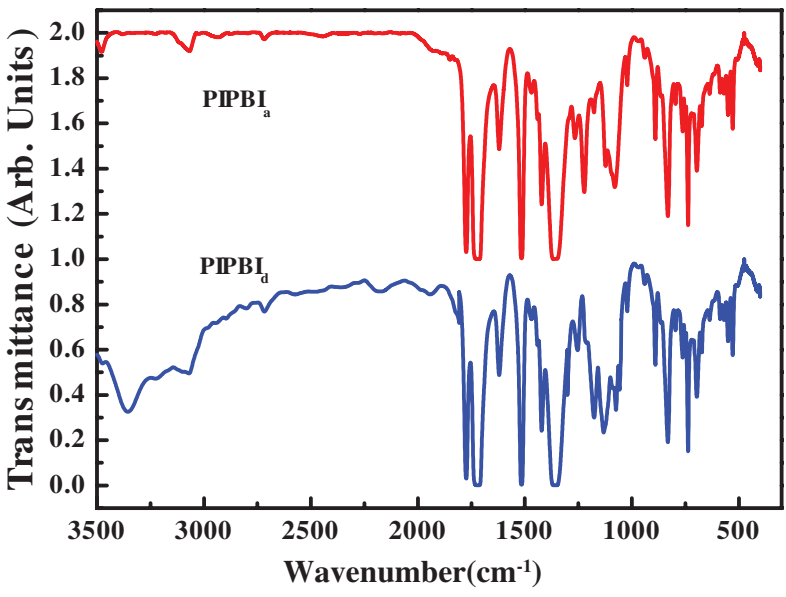

Figure 1: FTIR spectra of $\mathrm{PIPBI}_{\mathrm{a}}$ and $\mathrm{PIPBI}_{\mathrm{d}}$ films.

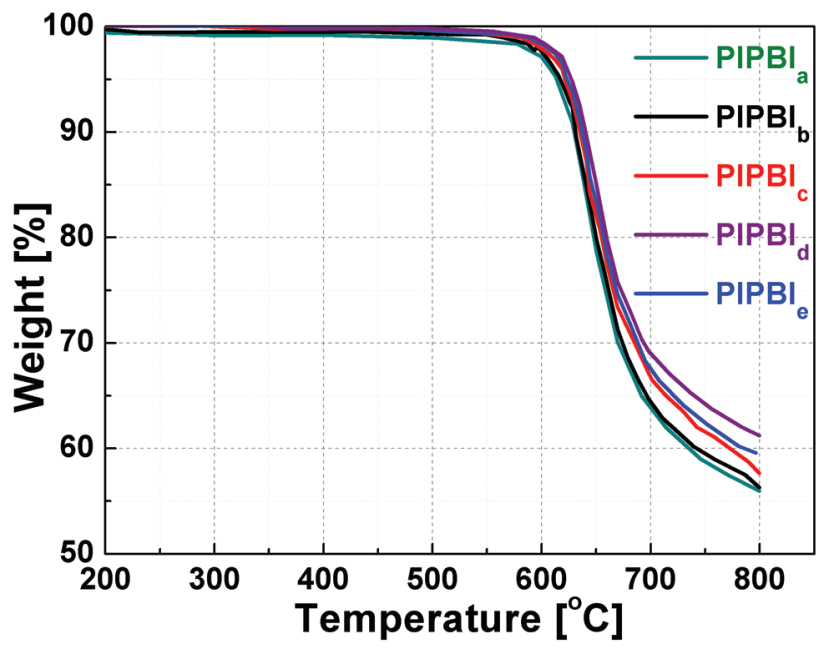

Figure 2: TGA curves of $\mathrm{PIPBI}_{\mathrm{a}} \sim \mathrm{PIPBI}_{\mathrm{e}}$ films.

Table 3: Thermal and mechanical properties of PIPBI films.

\begin{tabular}{lccccc}
\hline Entry & $\begin{array}{c}\mathrm{T}_{\mathrm{g}} \\
\left({ }^{\circ} \mathrm{C}\right)\end{array}$ & $\begin{array}{c}\mathrm{T}_{\mathrm{d}} \\
\left({ }^{\circ} \mathrm{C}\right)\end{array}$ & $\begin{array}{c}\text { Tensile } \\
\text { strength } \\
(\mathrm{MPa})\end{array}$ & $\begin{array}{c}\text { Tensile } \\
\text { modulus } \\
(\mathrm{GPa})\end{array}$ & $\begin{array}{c}\text { Elongation } \\
\text { at break } \\
(\%)\end{array}$ \\
\hline $\mathrm{PIPBI}_{\mathrm{a}}$ & 345 & 501 & $224 \pm 2$ & $4.7 \pm 0.05$ & $4.5 \pm 0.05$ \\
$\mathrm{PIPBI}_{\mathrm{b}}$ & 367 & 509 & $230 \pm 2.2$ & $5.2 \pm 0.07$ & $4.9 \pm 0.1$ \\
$\mathrm{PIPBI}_{\mathrm{c}}$ & 376 & 516 & $257 \pm 2.5$ & $5.4 \pm 0.07$ & $7.5 \pm 0.15$ \\
$\mathrm{PIPBI}_{\mathrm{d}}$ & 386 & 524 & $266 \pm 2.8$ & $6.8 \pm 0.15$ & $7.7 \pm 0.2$ \\
$\mathrm{PIPBI}_{\mathrm{e}}$ & 392 & 518 & $231 \pm 2.4$ & $6.0 \pm 0.1$ & $7.1 \pm 0.13$ \\
\hline & & & & &
\end{tabular}

to $20 \%$, a slight decrease of the $\mathrm{T}_{\mathrm{d}}$ at $518^{\circ} \mathrm{C}$ was observed, indicating that $\mathrm{T}_{d}$ of the PI film did not show a single trend. The decrease of $T_{d}$ when the PIPBI film with the ratio of DATFPBI content higher than $15 \%$ indicated that other factors rather than the composition of the polymer 


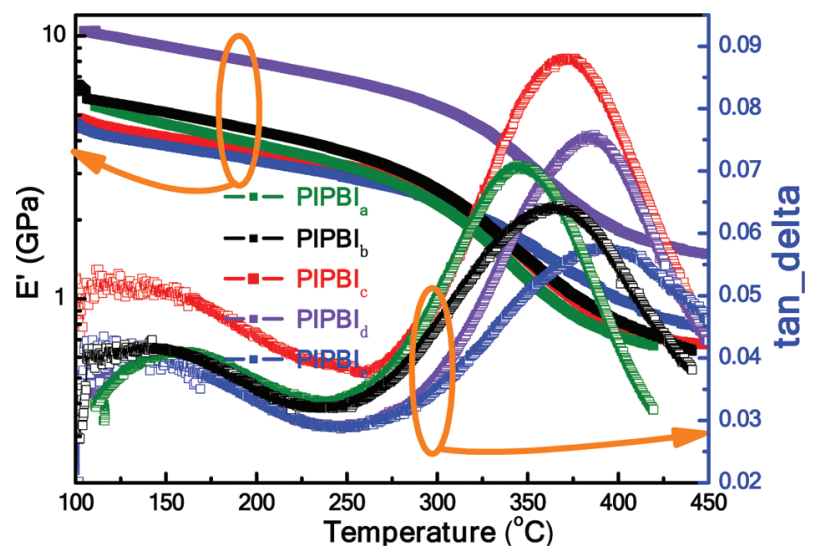

Figure 3: DMA curves of PIPBI $\sim \mathrm{PIPBI}_{\mathrm{e}}$ films.

affected the thermal stability of copolymer. The decreased $T_{d}$ of the may be caused by the copolymerization reaction that destroyed the regularity of the molecular chain.

\subsection{Dynamic mechanical behavior}

The DMA curves of the films are shown in Figure 3. The right vertical axis of Figure 3 indicates the $\tan \delta$-temperature correlation curve of the film. The peak position indicates the glass transition temperature $\left(\mathrm{T}_{\mathrm{g}}\right)$ of the film. $\mathrm{T}_{\mathrm{g}}$ of the PIPBI with different DATFPBI contents of $0 \%, 5 \%, 10 \%$, $15 \%, 20 \%$ was measured to be $345^{\circ} \mathrm{C}, 367^{\circ} \mathrm{C}, 376^{\circ} \mathrm{C}, 386^{\circ} \mathrm{C}$, $392^{\circ} \mathrm{C}$, respectively. A clear trend of $\mathrm{T}_{\mathrm{g}}$ increase with the addition of more DATFPBI content when the DATFPBI content was below $20 \%$. This could be attributed to the limited molecular chain movement of the polyimide with additional rigid DATFPBI, resulted in an increase $\mathrm{T}_{\mathrm{g}}$ of about $22-50^{\circ} \mathrm{C}$.

It was also found the storage modulus $\left(\mathrm{E}^{\prime}\right)$ of the PIPBI $_{a} \sim$ PIPBI $_{d}$ films increased while the DATFPBI content increased in the range of $100-450^{\circ} \mathrm{C}$ (Figure 3). The $\mathrm{E}^{\prime}$ values of BPPD/PPD-DATFPBI films decreased slightly in the temperature range of $100-280^{\circ} \mathrm{C}$ and drops dramatically at temperatures higher than $280^{\circ} \mathrm{C}$. Especially, the $\mathrm{E}^{\prime}$ value of the PIPBI film increased remarkably, which was much higher than those of the PIPBI $\sim$ PIPBI films that may be benefitted from the introduction of the rigid DATFPBI group into the polymer molecular chains. However, the $\mathrm{E}^{\prime}$ value of the PIPBI film was lower than that of the PIPBI, the main reason was possibly related to the irregularity of DATFPBI molecular chain and the poor reactive activity of the DATFPBI gave the low molecular weight of the PI precursor. The PIPBI film was found to be brittle when the DATFPBI content is too high. It should be mentioned that the PIPBI ${ }_{d}$ film with $15 \%$ of DATFPBI still possessed high storage modulus of $1.48 \mathrm{GPa}$ at about $450^{\circ} \mathrm{C}$, the good dynamic mechanical property is important for its applications in a high-temperature range.

\subsection{Mechanical property}

As shown in Table 3, the tensile modulus and tensile strength of the polymer film were observed to be strongly related to the proportion of the incorporated DATFPBI. For example, the modulus and strength of PIPBI $_{a}$ (without DATFPBI) were $4.7 \mathrm{GPa}$ and $224 \mathrm{MPa}$, respectively. When the content of DATFPBI was 5\%, the modulus and strength of the copolymer film were slowly increased to $5.2 \mathrm{GPa}$ and $230 \mathrm{MPa}$, respectively. When the content of DATFPBI was further increased to $10 \%$, the strength of the copolymer film dramatically increased to $257 \mathrm{MPa}$, which was $14.7 \%$ higher than that of PIPBI. When the content of DATFPBI was up to $15 \%$, the strength of the copolymerization film reached $266 \mathrm{MPa}$. The modulus of the copolymer film PIPBI $_{d}$ was increased to $6.8 \mathrm{GPa}$, which was $44.7 \%$ higher than that of PIPBI ${ }_{a}$. The increased tensile modulus and strength reflected the reinforcing effect of the rigid structures in the copolymer, which was widely studied in polymer modification. In our experiment, when the content ratio of DATFPBI was further increased, the modulus and strength of the copolymer film were dropped to $6.0 \mathrm{GPa}$ and $231 \mathrm{MPa}$, respectively it was because the reactivity of DATFPBI is lower than that of p-PPD. After the content of the DATFPBI exceeded 15\%, the molecular weight of the polymer began to reduce, and the film formation ability decreased, resulted in a decreased mechanical properties of the film $(38,39)$. The stressstrain curves of PIPBIa PIPBIe films shown in Figure 4, indicate that these PIs are amorphous polymers. The stress-strain curves indicate these three polymers are hard and flexible materials. The tensile results show that the rigid structural DATFPBI could improve the rigidity and regularity of the polymer chains. In brief, the PIPBI films exhibit outstanding mechanical properties due to the rigid structure and stronger molecular interchain interaction.

\subsection{Moisture absorption}

The PIPBI moisture absorption rates were almost constant from $1.4 \%$ to $1.43 \%$ even the DATFPBI content increases from $0 \%$ to $20 \%$, which was closely related to the structure of DATFPBI. It is known that the water uptake of poly(imide-benzimidazole) is up to $2.1 \%$ because the molecular chain of the polymer contains a hydrophilic 


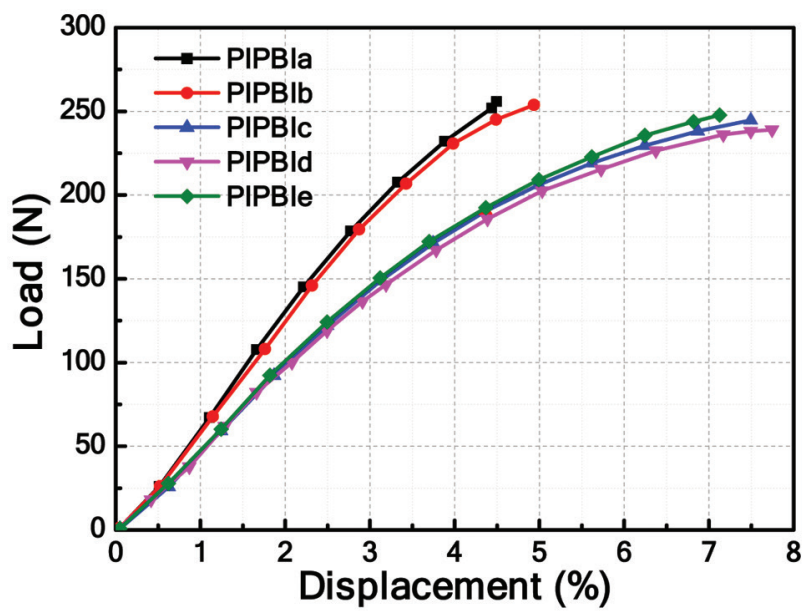

Figure 4: Stress-strain curves of $\mathrm{PIPBI}_{\mathrm{a}} \sim \mathrm{PIPBI} \mathrm{e}_{\mathrm{e}}$ films.

amino group (40). Theoretically, the copolymers contain DATFPBI with a hydrophilic amino group should have a higher moisture absorption ratio than that $(1.4 \%)$ of homopolymer PAPBI . However, the emoisture absorption rate of the obtained PIPBI film almost maintained at about $1.4 \%$, which can be explained by the fact that the hydrophobic trifluromethyl group in DATFPBI reduced the water uptake. Consequently, the interactions between the hydrophilic group and hydrophobic group made the hygroscopicity of the PI films almost constant.

\subsection{Dimensional stability}

Excellent dimensional stability over a wide temperature range is critical for thin film materials application in the microelectronics and aerospace industry. In general, the addition of an appropriate amount of a rigid third component for copolymerization can improve the dimensional stability of the material. As can be seen from Figure 5, the CTE of the polyimide film PIPBI gradually decreased from $20.2 \times 10^{-6} \mathrm{~m} /{ }^{\circ} \mathrm{C}$ to $15.3 \times 10^{-6} \mathrm{~m} /{ }^{\circ} \mathrm{C}$ with the DATFPBI content increasing. It can be explained by several reasons. Both the increased rigidity and the linear structure can be helpful in lowering the CTE. Furthermore, with the increase of the content of DATFPBI in the copolymer structure, the single phenylene group brought by $p$-PPD is reduced gradually, also resulting in a more rigid structure and lower CTE. The reduced CTE may be also related to the molecular chain orientation during the thermal imidization process. For higher proportion of the rod-like DATFPBI groups, the degree of orientation is believed to be higher in the copolymer, which also helps to lower the CTE.



Figure 5: Relationship between CTE of PIPBI films and DATFPBI content.

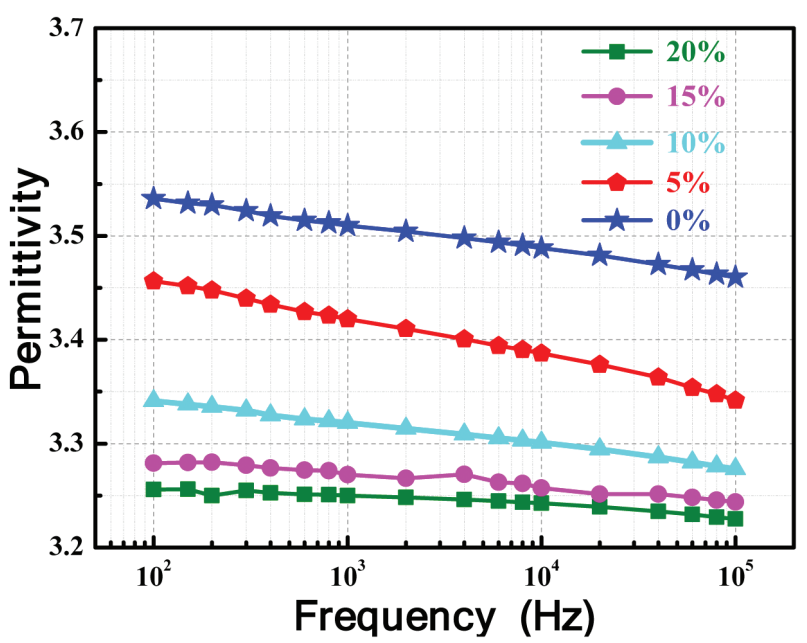

Figure 6: Effect of DATFPBI content on permittivity of the PIPBI films.

\subsection{Electrical property}

It can be seen from Figure 6 that the dielectric constant of the film decreased rapidly as the DATFPBI content increased. At a frequency of $10^{3} \mathrm{~Hz}$ initially, the film with $10 \%$ DATFPBI had a dielectric constant of 3.32, which was 5.4\% lower than that of the DATFPBI-free polyimide film (3.51). When the DATFPBI content increased to $15 \%$ and $20 \%$, the dielectric constants of the films were 3.24 and 3.21, respectively. It also could be noted that when the DATFPBI content was less than $15 \%$, the dielectric constant of the film decreased rapidly with the frequency rose up. While the DATFPBI content was higher than $15 \%$, the downward trend was not as sharp as the ratio below $15 \%$. This may be attributed to the introduction of the rigid DATFPBI ring with a trifluoromethyl group. The 
interactions between the rigid benzimidazole and fluoride substituted group made the polyimide film material more difficult to be polarized.

\section{Conclusions}

To improve the performances of the PI films used as flexible substrate for solar cell and high frequency communication applications, a copolymerization method by introducing a third rigid component DATFPBI has been studied. It is found that the imidization procedure and the heating rate are crucial for the properties of the BPDA/PPD-DATFPBI films. The best heat treatment process to prepare BPDA/PPDDATFPBI polyimide film is a four-step heat treatment. We find that $\mathrm{T}_{\mathrm{g}}$ of the PI films increases from 345 to $392^{\circ} \mathrm{C}$ when the DATFPBI content is up to $20 \%$. The tensile modulus and strength of the copolymer film are also reinforced greatly when the content of rigid DATFPBI component is increased to $15 \%$. Additionally, the hygroscopicity, dimensional stability and electrical property of the PI films are improved slightly. The optimized content of the rigid DATFPBI component in the PI films is found to be $15 \%\left(\mathrm{PIPBI}_{\mathrm{d}}\right.$ ), for which the prepared materials shows performance of $\mathrm{T}_{\mathrm{g}}$ at $368^{\circ} \mathrm{C}$, a tensile modulus of $6.8 \mathrm{GPa}$, a CTE of $16.8 \mathrm{ppm} / \mathrm{K}$, a moisture absorption of 1.42 and an initial $\mathrm{T}_{\mathrm{d}}$ of $524^{\circ} \mathrm{C}$. To summarize, the overall performance of the PI films has been improved significantly by adding the rigid DATFPBI, which can be a potential candidate for the flexible substrates of solar cell process.

Acknowledgements: The work was supported by the ShenzhenBasicResearchGrantno.JCYJ20170818114324998, the Key Charateristic and Innovative Scientific Research Project of Guangdong Provincial Education Department no. 2017GKTSCX080, and the Major Social Welfare Project of Zhongshan No. 2018B1020.

\section{References}

1. Liu H., Zhai L., Bai L., He M., Wang C., Mo S., et al., Synthesis and characterization of optically transparent semi-aromatic polyimide films with low fluorine content. Polymer, 2019, 163, 106-114.

2. Zhang X.-M., Liu J.-G., Yang S.-Y., A review on recent progress of R\&D for high-temperature resistant polymer dielectrics and their applications in electrical and electronic insulation. Rev. Adv. Mater. Sci., 2016, 46(1), 22-38.

3. Li Q., Chen L., Gadinski M.R., Zhang S., Zhang G., Li H.U., et al., Flexible high-temperature dielectric materials from polymer nanocomposites. Nature, 2015, 523(7562), 576-579.
4. Lei X., Chen Y., Qiao M., Tian L., Zhang Q., Hyperbranched polysiloxane (HBPSi)-based polyimide films with ultralow dielectric permittivity, desirable mechanical and thermal properties. J. Mater. Chem. C, 2016, 4(11), 2134-2146.

5. Yu X., Liang W., Cao J., Wu D., Mixed rigid and flexible component design for high-performance polyimide films. Polymers, 2017, 9(9), 451.

6. Peng X., Xu W., Chen L., Ding Y., Chen S., Wang X., et al., Polyimide complexes with high dielectric performance: Toward polymer film capacitor applications. J. Mater. Chem. C, 2016, 4(27), 6452-6456.

7. Bisoi S., Mandal A.K., Singh A., Banerjee S., Gas separation properties of Troeger's base-bridged polyamides. e-Polymers, 2017, 17(4), 283-293.

8. Dasgupta B., Banerjee S., A study of gas transport properties of semifluorinated poly (ether imide) membranes containing cardo diphenylfluorene moieties. J. Membrane Sci., 2010, 362(1-2), 58-67.

9. Dasgupta B., Sen S.K., Banerjee S., Gas transport properties of fluorinated poly (ether imide) membranes containing indan moiety in the main chain. J. Membrane Sci., 2009, 345(1-2), 249-256.

10. Ghosh A., Banerjee S., Thermal, mechanical, and dielectric properties of novel fluorinated copoly(imide siloxane)s. J. Appl. Polym. Sci., 2008, 109(4), 2329-2340.

11. Takekoshi T., Polyimides. CRC Press, 2018, 7-48.

12. Yokota R., Photosensitive Polyimides. Routledge, 2017, 49-95.

13. Wu H., Khdour M., Apsangi P., Yu H., High-frequency magnetic thin-film inductor integrated on flexible organic substrates. IEEE T. Magn., 2017, 53(11), 1-7.

14. Zhu W., Park S., Yogeesh M.N., McNicholas K.M., Bank S.R., Akinwande D., Black phosphorus flexible thin film transistors at gighertz frequencies. Nano Lett., 2016, 16(4), 2301-2306.

15. Ahne H., Rubner R., Photosensitive Polyimides. Routledge, 2017, 13-48.

16. Ding M.X., Polyimides: Chemistry, Relationship between Structure and Properties and Materials. Science Press, Beijing, China, 2006.

17. Feurer T., Reinhard P., Avancini E., Bissig B., Löckinger J., Fuchs P., et al., Progress in thin film CIGS photovoltaics - Research and development, manufacturing, and applications. Prog. Photovoltaics, 2017, 25(7), 645-667.

18. Ma P., Wei N., Yang Z., Zhang P., Gang L., Lei Q., et al., Preparation and characterization of polyimide $/ \mathrm{Al}_{2} \mathrm{O}_{3}$ hybrid films by sol-gel process. J. Appl. Polym. Sci., 2010, 108(2), 705-712.

19. Fay C.C., Stoakley D.M., Clair A.K.S., Molecularly Oriented Polymeric Thin Films for Space Applications. High Perform. Polym., 2008, 11(1), 145-156.

20. Zhao W., Xu Y., Song C., Chen J., Liu X., Polyimide/mica hybrid films with low coefficient of thermal expansion and low dielectric constant. e-Polymers, 2019, 19, 181-189.

21. Khatua S.C., Maiti S., High-performance polymer films. III. Preparation and characterization. J. Appl. Polym. Sci., 2001, 82(4), 976-988.

22. Ding M., Polyimides: Synthesis of Monomer, Polymerization Method and Preparation of Materials. Science Press, Beijing, China, 2011.

23. Wang Y., Lu G., Wang W., Cao M., Luo Z., Shao N., et al., Molecular design and synthesis of thermotropic liquid crystalline 
poly(amide imide)s with high thermal stability and solubility. e-Polymers, 2017, 17, 199-207.

24. Kohno T., Otani A., Hosoma T., Inoue H., Aromatic polyimide film and polyimide/copper foil composite sheet. US patent, US 5849397, US patent: Google Patents, 1998.

25. Ishii J., Takata A., Oami Y., Yokota R., Vladimirov L., Hasegawa M., Spontaneous molecular orientation of polyimides induced by thermal imidization (6). Mechanism of negative in-plane CTE generation in non-stretched polyimide films. Eur. Polym. J., 2010, 46(4), 681-693.

26. Numata S., Miwa T., Thermal expansion coefficients and moduli of uniaxially stretched polyimide films with rigid and flexible molecular chains. Polymer, 1989, 30(6), 1170-1174.

27. Chen D., Wang R., Tjiu W.W., Liu T., High performance polyimide composite films prepared by homogeneity reinforcement of electrospun nanofibers. Compos. Sci. Technol., 2011, 71(13), 1556-1562.

28. Dai X., Bao F., Jiao L., Yao H., Ji X., Qiu X., et al., High-performance polyimide copolymer fibers derived from 5-anino-2-(2-hydroxy4-aminobenzene)-benzoxazole: Preparation, structure and properties. Polymer, 2018, 150, 254-266.

29. Wang S., Zhou H., Dang G., Chen C., Synthesis and characterization of thermally stable, high-modulus polyimides containing benzimidazole moieties. J. Polym. Sci. A1, 2009, 47(8), 2024-2031.

30. Li Y., Xu G., Cui C., Li Y., Flexible and semitransparent organic solar cells. Adv. Energ. Mater., 2018, 8(7), 1701791.

31. Choi H., Chung I.S., Hong K., Park C.E., Kim S.Y., Soluble polyimides from unsymmetrical diamine containing benzimidazole ring and trifluoromethyl pendent group. Polymer, 2008, 49(11), 2644-2649.

32. Nishino T., Kotera M., Inayoshi N., Miki N., Nakamae K., Residual stress and microstructures of aromatic polyimide with different imidization processes. Polymer, 2000, 41(18), 6913-6918.

33. Fay C.C., St. Clair A.K., Dimensionally stable polyimide copolymers for microelectronics applications. J. Appl. Polym. Sci., 1998, 69(12), 2383-2393.

34. Miwa T., Okabe Y., Ishida M., Effects of precursor structure and imidization process on thermal expansion coefficient of polymide (BPDA/PDA). Polymer, 1997, 38(19), 4945-4949.

35. Chung H., Joe Y., Han H., The effect of curing history on the residual stress behavior of polyimide thin films. J. Appl. Polym. Sci., 1999, 74(14), 3287-3298.

36. Chen K.M., Wang T.H., King J.S., Hung A., Effect of imidization temperature on properties of polymide films. J. Appl. Polym. Sci., 1993, 48(2), 291-297.

37. Takekoshi T., Polyimides. Springer Berlin Heidelberg, Berlin, Heidelberg, 1990.

38. Khatua S.C., Maiti S., High performance polymer films 4. Mechanical behavior. Eur. Polym. J., 2002, 38(3), 537-543.

39. Hasegawa M., Fujii M., Wada Y., Approaches to improve the film ductility of colorless cycloaliphatic polyimides. Polym. Advan. Technol., 2018, 29(2), 921-933.

40. Wang C., Zhao X., Tian D., Wang D., Chen C., Zhou H., Synthesis and characterization of novel polyimides derived from 4, 4'-bis (5-amino-2-pyridinoxy) benzophenone: effect of pyridine and ketone units in the main. Des. Monomers Polym., 2017, 20(1), 97-105. 